\title{
Customers Perceptions of Staying at a Lifestyle hotel
}

\author{
Wu Sining ${ }^{1}$ \\ ${ }^{1}$ Beijing International Studies University, Finance, No. 1, Nanli, Dingfuzhuang, Chaoyang District, Beijing, China
}

\begin{abstract}
The purpose of this research was to understand Chinese customers' views on the lifestyle hotel industry. The study objectives were to a) investigate reasons people stay in lifestyle hotels, b) what customers expect from lifestyle hotels, and c) inspire managers to improve their business model to give customers a better experience. 115 respondents participated in the survey who had stayed at lifestyle hotels. The study found that people stay at lifestyle hotels because they provide a welcoming environment and offer plenty of entertainment. Customers indicated that they would like the hotels to provide more family activities to enhance the quality of their stay. It was also found that managers need to provide highly personalized services to enhance the brand image, which in turn increases the uniqueness of the hotel and attracts customers.
\end{abstract}

\section{INTRODUCTION}

Lifestyle hotels are a lodging concept that has gradually emerged in recent years. It usually integrates social interaction among customers, greater personalized service, in a more relaxed, intimate setting, unlike large-scale hotels. Lifestyle hotels are boutique hotels that incorporate life elements and daily activities to create a rich experience for guests.

A large part of the research on lifestyle hotels is defining how they differ from other lodging accommodations. Some scholars have also analyzed the reasons for their popularity under the premise of "lifestyle hotels are popular [1]. However, few studies have confirmed why customers choose lifestyle hotels over other lodging types and the services that they want to be provided during their stay. Therefore, this research will focus on understanding customers' views on lifestyle hotels to inspire managers.

\section{REVIEW OF LITERATURE}

One's body, clothes, speech, leisure pastimes, eating and drinking preferences, home, car, choice of holidays, etc., are to be regarded as indicators of the individuality of taste and sense of the "lifestyle" of consumers[2]. The concept of "lifestyle" was put forward earlier, and it has gradually evolved into various products.

PricewaterhouseCoopers[3] defines lifestyle hotels as having a: unique identity, modern decor, smaller properties with a limited number of guest rooms, high levels of personal service, reflective of the personality/style of their designers and/or operators and owners, and stylish design-led architecture and interiors, often offering high-quality, high-tech in-room facilities. After that, the proportion of lifestyle hotels has gradually increased, and this concept has gradually become popular [4-6].

Lifestyle hotels are often confused with theme hotels and boutiques[7-9]. This leads to less research on lifestyle hotels and more research on theme hotels and boutique hotels. De Klumbis[4] briefly distinguishes the difference between lifestyle hotels, boutique hotels, and design hotels, but there is no detailed explanation of lifestyle hotels in the subsequent research. To some extent, this phenomenon shows that lifestyle hotels combine the common characteristics of theme hotels and boutique hotels. For user surveys of lifestyle hotels, the model of big data plus sentiment scores are usually adopted [10-11]. Although this model can understand the user's experience after staying in the hotel, it ignores the user's "habit" factor, that is, the user's subjective intention.

For the purpose of this study, I adopted the statement of the Boutique and Lifestyle Accommodation Association[7] that lifestyle hotels are boutique hotels. In the BLLA report, lifestyle hotels are defined as: a) Innovative, b) Less about the brand, c) More personalized service, and) Contemporary/Modern. BLLA believes that "A lifestyle hotel is more contemporary, with unusual design and architecture, and a high level of technology. A lifestyle hotel offers more ancillary services and focuses on wellness and life-enrichment." On the other hand, boutique hotels are defined as: a) Cultural/Historic/ Authentic, b) Unique design that is not based on a franchised chain design, c) Interesting, d) providing unique Services. There are also many high-quality inroom features, social spaces (such as living rooms for guests to relax), libraries, and social events

\section{OBJECTIVE OF THE STUDY}

Lifestyle hotels are growing in popularity among consumers when choosing lodging accommodations 
compared to the large traditional hotels. When interviewing managers of lifestyle hotels for this research paper, the author found that managers tend to "give" customers an experience based on their personal tastes and preferences instead of providing services according to the needs and expectations of the customer. Therefore, the results of this study could be used to motivate managers to instead provide experiences that are designed to meet the tastes, preferences, and expectations customers expect from lifestyle hotels. The three objectives below will be used to better understand why customers are attracted to lifestyle hotels.

Objective 1: Investigate the reasons people stay in lifestyle hotels as well as their personal preferences. The results may help hotel managers effectively refine the amenities preferred when staying in a lifestyle hotel. In the questionnaire, these two points are broken down according to the $5 \mathrm{~W}$ principle: what, why, who, where, and when. And put forward separately according to five questions.

Objective 2: Understand what the customers of lifestyle hotels expect from the hotel. This factor is defined as the way and quality of service that can attract customers. Services can be divided into paid items and free items, among which souvenirs are not only paid items but can also improve the brand of the hotel, so they are listed separately. Since what affects service is not only the quality of service but also customer habits.

Objective 3: Inspire managers to improve their business models and give customers a better experience. This goal should be an effective recommendation that integrates the comprehensive results of objectives 1 and 2 .

\section{METHODOLOGY}

\subsection{Sample}

Because this study aims to investigate customer perceptions of lifestyle hotels, all participants must have some experience with lifestyle hotels.

\subsection{Procedures}

To achieve the goal, the author developed a questionnaire. Insightworks assisted in sending out the questionnaires. The responses were also collected through social media platforms. The response period was one week. The online questionnaire was randomly sampled in each city, and at the same time, the crowd funnel model is used in the first question to include only those who have stayed at a lifestyle hotel. The sample included 19 cities from 15 provinces in China, using a random sampling method which yielded 115 completed questionnaires.

\subsection{Measures}

The questionnaire was developed after discussions between hotel managers and related researchers. The definitions and classifications in the questionnaire were modified according to the habits of Chinese consumers that may be of interest to hotel managers. The wording of the questionnaire was also refined under the guidance of a professor at a hospitality and tourism program in the United States.

Demographic data collected included age, gender, occupation, income, and hometown. To make the interviewees feel relaxed, the personal demographic data was placed at the end of the survey. The demographic data may also help lifestyle hotels' marketing efforts.

The specific survey questions on the survey are listed in this paragraph. The first question asked, "What type of hotel have you stayed in?" The second question asked, "Compared to other hotels on the market, why did you choose a lifestyle hotel?" The third question asked, "Who do you usually travel with when you stay in a lifestyle hotel?" The fourth question asked, "Do you choose to stay at a lifestyle brand hotel so you could participate in leisure actives such as sightseeing, shopping, and so forth?" The fifth question asked, "What are the most important characteristics of a lifestyle hotel?" Choose the most important characteristic of a lifestyle hotel?" The sixth question asked, "How did you find about the hotel you stayed at?" The seventh question asked, "Do you buy souvenirs when staying at a lifestyle hotel?" The eighth question asked, "What kind of souvenir?" The ninth question asked, "What activities do you do when you stay at a lifestyle hotel, such as shopping, entertainment, and so forth? Please explain." The tenth question asked, "Were you attracted to the hotel for its personalized service? (For example, one-to-one service, able to talk directly with the operator)" The eleventh question asked, "Were you attracted to the hotel for its personalized service?" The twelfth question asked, "Please explain the advantages and disadvantages of staying at the hotel." The thirteenth question asked, "Your age range." The fourteenth question asked, "Your gender." The fifteenth open-ended question asked respondents to state their occupation." The sixteenth question asked the respondent to indicate "Your monthly income level." The seventeenth question asked the respondent to indicate to "Please select city," in which they stayed at a lifestyle hotel.

The following questions were used to accomplish objective 1: question 2 , question 3 , question 4 , question 5 , and question 6 . The following questions were used to accomplish objective 2: question 7, question 8, question 9, question 10 , and question 21 . The following questions were used to accomplish objective 3: question 12 .

\subsection{Analysis}

SPSS was used to analyze the data that was collected from the survey.

\subsection{Results}

115 people participated in the survey. All 115 respondents had stayed in a lifestyle hotel. There were 50 respondents aged 41-50, which comprised almost half of the sample. 46 respondents were aged 26-30, which comprised $40 \%$ of the sample. Among the participants, there were 45 males and 70 females. There were 74 participants with a 
monthly income of more than 10,000, which was $64 \%$ of respondents. 36 people responded that held management positions, which accounted for one-third of the total number of participants. There were 14 professionals and Technical/R\&D who responded to the survey. The largest number of participants are from Beijing, Guangdong, and Shanghai, with 39 in Beijing, 26 in Guangdong, and 20 in Shanghai.

Investigate the reasons people stay in lifestyle hotels as well as their personal preferences. The second to sixth questions on the survey were designed to complete this objective. The second question asked the respondents why they stayed in a lifestyle hotel. Among them, 85\% $(n=100)$ of respondents chose that they "Want to experience the unique atmosphere," and $70 \%(n=81)$ respondents chose "I think this hotel is better value for money." The third question inquired about whom the respondent stays with at a lifestyle hotel. There were $67.8 \%$ $(\mathrm{n}=78)$ respondents who chose to come to lifestyle hotels with their husbands or wives, and 59\% $\quad(n=68)$ respondents who stayed with friends, but $86 \%(n=99)$ who were unwilling to come to lifestyle hotels with business partners. The fourth question wanted to know if the respondent attends events when staying at a lifestyle hotel. There were $97.4 \%(n=112)$ of respondents who chose to participate in activities when they stay in a lifestyle hotel. The fifth question was to find out what respondents considered to be the most important attributes of a lifestyle hotel. According to respondents, there were 53\% $(n=61)$ who indicated that the most important feature of the hotel was the "environment (such as hygiene, safety). The sixth question asked how did you find out about the hotel you stayed at. There were $87.8 \%(n=100)$ who chose the hotel due to its popularity and $64 \%(n=74)$ who said that they search for lifestyle hotels when traveling.

Objective 2 was to understand what the customers of lifestyle hotels expect from the hotel. Questions seventh to the eleventh focus on achieving this objective. The seventh question asked if the respondent would buy a souvenir from a lifestyle hotel, and if the respondent chooses yes, the eighth question will go on to ask what type of souvenir the customer would choose. There were $74.8 \%(n=86)$ respondents who chose to buy souvenirs when they checked into the hotel, and $63.5 \%(n=73)$ chose the local souvenirs where the hotel was located. The ninth question asked respondents to fill in the activities they had participated in while at the lifestyle hotel. $43.5 \%(n=50)$ people said they would shop when they checked into the hotel, and $47 \%(n=54)$ chose entertainment. The tenth question asks respondents to choose whether they are attracted to personalized services. If respondents choose yes, the eleventh question asks them to check off the personalized services they have experienced. $85.2 \%(\mathrm{n}=98)$ respondents were attracted by personalized service, and $75.7 \%(n=87)$ of them liked food with various characteristics. The number of people who like one-to-one service, talking with managers, and providing navigation services to nearby attractions is evenly divided, and more than half.

Objective 3 was to inspire managers to improve their business models and give customers a better experience. The twelfth question was open-ended and asked respondents to write what they thought were the advantages and disadvantages of lifestyle hotels. Regarding the advantages of lifestyle hotels, $24.3 \%(n=28)$ people think that the quality of service was good, $24.3 \%$ $(n=28)$ are attracted by its uniqueness, 33.\% $(n=38)$ people like its atmosphere, and 13\% $(n=15)$ thought the hotel had its unique characteristic. At the same time, $24.3 \%$ $(n=28)$ people would not choose to stay at a lifestyle hotel because of their higher prices, and $15.7 \%(n=18)$ people also suggested that lifestyle hotels have a smaller, more targeted, and selective clientele. Respondents believe that lifestyle hotels sometimes focus too much on their themes or features while ignoring other aspects, such as a certain vintage atmosphere with fixtures and furnishings that were outdated. At the same time, a monotonous theme without variation will make customers feel bored. Some mentioned in the questionnaire that theme hotels are only obsessed with themes or have only one simple theme, not the overall atmosphere.

\subsection{Discussion}

The purpose of this research study was to determine Chinese customers' preferences for lifestyle hotels. To accomplish such a purpose, a survey was sent to those who had stayed at lifestyle hotels. There were three study objectives to accomplish this study.

Based on the results of Objective 1, it was found that customers prefer to experience a unique atmosphere in a lifestyle hotel. They usually visit lifestyle hotels with their friends and family to experience it. Therefore, managers might make changes to the hotel that are more familyoriented. Such as adding more group activities or family activities and more convenience in facilities for children or the elderly. Almost all customers chose to attend local events while staying at the hotel. Lifestyle hotel customers also pay more attention to the actual safety or hygiene conditions, so managers need to pay close attention to providing a safe and clean hotel if they want guests to return for another stay. Most of the respondents learned about the hotel through word of mouth marketing from those who had stayed at a particular lifestyle hotel unless they happen to come across a hotel of their choice during their travels purely by chance. Hotel managers should consider devoting more time to brand management, to differentiate themselves from competing brands to attract more customers.

Based on the results of Objective 2, it was found that many customers buy some souvenirs during their stay. However, customers focus more on the local souvenirs than those offered by the hotel, so managers should find ways to provide souvenirs from local businesses in their gift shop. During their stay, many customers choose to shop or participate in some entertainment activities outside of the hotel, so managers might consider offering entertainment activities inside the hotel to increase their capture rate, meaning customers will spend more time and money in the hotel during their stay which would increase profits. Most customers want personalized service, especially when it comes to offering a greater variety of food choices if there is a restaurant in the hotel. Hotel 
managers should also take the time to interact with their guests to find out if their guests are enjoying their stay and seek feedback on how the hotel can improve the quality of service it provides to future customers. In the restaurant industry, this is known as "touching tables," where the manager interacts with customers to see if they are happy with the quality of food and personal service they are experiencing. If they are not, the manager can immediately address the problems so that the guest leaves satisfied with their experience and increases the probability of them returning.

Objective 3 was to inspire managers to improve their business models and give customers a better experience. There were suggestions provided by respondents for ways in which managers of lifestyle brands could provide customers with a better experience. Respondents suggested that lifestyle hotels emphasize how they are different from other hotel concepts by providing a unique experience compared to other hotel brands. However, customers must be reassured that paying more to stay at a lifestyle hotel is worth it compared to what they may pay to stay at other hotel brands in the market. Based on customer feedback, the quality of service they are being provided is the key if hotel managers want them to return and promote the hotel through word-of-mouth marketing. Unless a lifestyle hotel can refresh the body, mind, and spirit of the guests they may choose to stay at those hotels who can satisfy their needs and expectations.

\subsection{Limitations}

In this study, the sample size has a large limitation. Insufficient sample size may result in inaccurate results. At the same time, the subjective questions of the questionnaire did not establish a quantitative standard, resulting in a vague direction of results.

\subsection{Recommendations for Future Research}

Future studies should attempt to have a larger sample size to have a more accurate profile of the lifestyle hotel customers. The views of hoteliers can be included in the research. A future study should also compare the tastes and preferences of lifestyle hotels between hoteliers and customers so that hoteliers can better understand customers' needs. In addition, the main target of this study is Chinese customers, and the hotel is also located in China. Future studies can include more geographically located customer groups to enhance the universality of the results.

\section{CONCLUSIONS}

This study investigated Chinese customers' perceptions of lifestyle hotels using a survey questionnaire, to understand customers' reasons for staying in lifestyle hotels, their perceptions of lifestyle hotels, and to make suggestions to managers based on this. This study builds on the previous work by placing more emphasis on customers' subjective feelings and allowing hotel managers to understand more about customer needs from the customer's perspective. Based on the study objectives, it was found that hotel environment and recreational activities are important factors that influence customers' perception of lifestyle hotels. With family customers making up a larger portion of the clientele, managers need to increase family activities. It is crucial to establish a brand image as customers will choose lifestyle hotels that are more visible. This image can be built through more personalized service. The ambiance is a top priority for lifestyle hotels, and a single theme or environment can reduce the ambiance and give customers a bad experience.

\section{References}

1. Milburn, R., Stotts, S., Hall, L, Standing out in a crowd: PricewaterhouseCoopers' fourth European Lifestyle Hotel Survey 2006. Hospitality DirectionsEurope Edition, 14, 1-12(2006)

2. Mike, Featherstone, Lifestyle and consumer culture. Theory, Culture \& Society (1987)

3. International $\mathrm{C}$, Mapping an innovative niche sector in Europe, Goodbye boutiques and hello lifestyle hotels?, Hospitality Directions - Europe Edition(2002)

4. De Klumbis, D. F, Seeking the "ultimate hotel experience", Working paper,1-13, Spain (2002)

5. Milburn, R., Hall, L., The secret of lifestyle hotels' popularity is simple: they are in tune with the needs of the new, complex consumer. Hospitality Directions-Europe Edition, 12, 1-11(2005)

6. Fawaz, Z. R, Lifestyle hotels: The emergence of a new creative clas. (2015)

7. Day, J., Quadri, D., Jones, D. L. Boutique and lifestyle hotels: Emerging definitions. BLLA, Boutique \& Lifestyle Lodging Association. (2012)

8. Götz, I. What are the differences and similarities of boutique and lifestyle hotels for professionals, consumers and students (2015)

9. Santos, M. V. P. Negative customer experience in lifestyle hotels: A Netnography perspective (2019)

10. Baek, J., Choe, Y., Ok, C. M.. Determinants of hotel guests' service experiences: an examination of differences between lifestyle and traditional hotels. Journal of Hospitality Marketing \& Management, 29(1), 88-105.(2020)

11. Hua, W., Qu, H.. A gap analysis on Generation $Y$ customer expectations and perceptions towards lifestyle hotels (2011) 